\title{
Watching Battlestar Galactica in Australia and the Tyranny of Digital Distance
}

\author{
Dr Tama Leaver \\ Department of Internet Studies, \\ Curtin University \\ t.leaver@curtin.edu.au \\ http://www.tamaleaver.net
}

This is a post-print of a peer-reviewed article which appears in Media International Australia, 126 , February 2008, pp. 145-154. This post-print has been created with the permission of the editor of Media International Australia.

In 1966, conservative Australian historian Geoffrey Blainey coined the term 'the tyranny of distance' to describe the fundamental role that the geographic distance from the United Kingdom - the cultural and economic centre of 'Empire'-played in forming the character and cultural identity of Australia's white population. At the beginning of the twenty-first century, distance is now relative to life as part of a global village; the World Wide Web, email, and many other technologies have made real-time information-heavy communication and commerce the norm. While the infrastructure of current information and communication technologies has made distance far less structurally important, many existing policies and practices still operate as if centred on moving goods at the speed of physical shipping rather than allowing for information moving at almost the speed of light down an optical cable. In an era when the tyranny of distance should be meaningless, certainly in terms of digital products, I will argue instead that the Australian media landscape is marked by a prevailing tyranny of digital distance which occurs when the potential and, indeed, expectation of nearsynchronous global distribution of media is not fulfilled due to arbitrary boundaries which began as geographic but are now entirely in the economic and political domain.

The North American-produced television series Battestar Galactica (BSG), re-imagined for the twenty-first century (based an original 1970s series), has consistently been at the cutting edge of television, and in terms of its use of digital communication tools to enhance and expand viewers' potential interaction with each other and the shows' creators. While fan communities have long been exemplars of media-centred creativity and interaction (Jenkins, 1992), the internet has facilitated a massive increase in both the speed of interaction and breadth of fan involvement. To engage their viewers, executive producer, lead writer and show-runner Ronald D. Moore and the BSG team utilise not just written blogs and production-side video blogs, but also create episodic commentary podcasts, make deleted scenes available online, and have even put two full episodes online for free viewing. Similarly, BSG was one of the first shows available via the US version of Apple's online iTunes Store. The show's location within the science fiction genre immediately positions it favourably with a large potential fan base, and the show's creative team have actively courted and strengthened that connection. The BSG fan community is sizable, including those who consume both the television show itself and the officially produced extra material, as well many members who actively create and discuss their own derivative fan commentaries and creations, ranging from detailed blog commentaries on particular episodes all the way to special effects laden videos set in the BSG universe. Moreover, the key means of communication and connection for BSG fans is using online discussion tools, ranging from the official forums hosted by SciFi.cor through to blogs and other conversation spaces attached to related digital media. Given the online nature of this fandom, the fan community 
is not limited to North America, but also includes active fans from across the globe, including a considerable number from Australia. However, while the fan community can interact in real time globally and the extra material provided by BSG's producers, including the podcast commentaries and video blogs, are availably immediately at all corners of the internet, there is still a delay of often six months or longer between the North American airdate of a particular episode of BSG and its eventual screening in Australia. Moreover, while most official webbased extra content created by the BSG producers has been free for everyone, when a series of ten three to four minutes long 'webisodes' were released online in 2006 to reinvigorate interest prior to the third season premiere in the US, fans quickly discovered that access to this content was only available to those viewing from computers within the United States. Using these two disjunctions between a global fan community and television content restricted along national boundaries, I shall examine BSG in terms of spoilers, the building of viewer loyalty, and its unlawful distribution via peer to peer file-sharing networks, concluding with some speculation suggesting that overcoming the tyranny of digital distance is in the interests of both Australia fans and media distributors.

The notion of spoilers or spoiling in relation to television came into being due to the time differences between East and West Coast viewers in the United States. As networked digital communication emerged, comments from East Coast viewers, who got a particular television series three hours before those in California, started to arrive on the West Coast before the series was screened. Given that this practice could ruin the surprises and twists in a good TV show, annoyed West Coast viewers rapidly informed their East Coast correspondents to warn them about material which could potentially spoil the viewing experience; hence the "* SPOILER WARNING *' which often appears at the top of emails, blog entries and other digital communication about recently-aired television (Jenkins, 2006: 30). Conversely, it is also worth noting that the practice of spoiling is not just an accidental or negative one. Indeed, the work of media scholars such as Henry Jenkins (2006), looking at the spoiler community around Survivor, or Jonathan Gray and Jason Mittell (2007), examining the networks of consumption and spoiling around Lost, emphasises that the practice of purposeful self-spoiling undertaken by media consumers seeking out details of their favourite televisioncentred media franchises before the official US airdates, is rapidly becoming a popular fan pastime. This practice is hardly surprising given how much time and energy studios put into advertising television programmes, hyping the latest unforeseen plot twist to the point of frenzy. However, what both spoiler warnings and the practice of self-spoiling fans emphasise is the notion that the question of whether to be spoilt or not should be left to the individual viewer to decide.

In Australia, viewers of US or UK produced television are increasingly unable to avoid spoilers. For critically acclaimed shows like BSG or The Sopranos, plot developments and major twists in television series are often reported by commentators and critics in mainstream presses as a matter of practice. Given that Australian news media often recycle US material and that many Australian internet users rely on services like Google News which cobble together popular material from the web globally, it might be possible to purposefully avoid reading about a particular show for a week or two, but it is increasingly difficult, if possible at all, to avoid media reports, fan commentaries and blog posts about popular television series for the six months or longer it takes Australian broadcasters to screen shows like BSG. While it might be possible to retort that knowledge about plot developments doesn't necessarily ruin the viewing experience, the recent controversy about potential spoilers being released before the distribution of the final Harry Potter novel suggests otherwise. When pirated copies of the last Harry Potter book appeared online and newspapers, including The New York Times, 
published reviews with plot details before the official release of the book, there was a very public outcry from fans and J. K. Rowling alike (Cuslidge and Weiss, 2007). As this example attests, the right of readers and viewers to enjoy media narratives for themselves is of considerable cultural value. Yet, as canny media producers increasingly put considerable effort into reinforcing connections between online fan communities and their favourite television programs, the tyranny of digital distance is apparent as Australian fans must choose between avoiding the larger online fan community or having key plot developments spoilt from afar. As one Australian media fan recently wrote: 'We are sick of finding out who killed Laura Palmer or who shot Mr. Burns months before we finally see the episode screened on free to air' (Wells, 2007).

Increasingly, the plight of fans struggling to participate in online communities centred on USor UK-produced media, but also trying to avoid spoilers, is a dilemma being shared by more and more people as marketers, distributors and producers actively seek to foster fans loyal to their particular series or media franchise. In his seminal monograph Convergence Culture, Henry Jenkins argues that industry insiders are increasingly moving away from relying exclusively on examining the number of viewers per television show, to a model which also looks at the dedication with which viewers engage with TV (2006: 74-6). This model is marked by two extremes: 'zappers' on the one hand who constantly flick across television channels, rarely watching a whole episode of anything, but often watching a lot of bits and pieces; and 'loyals' who may watch less actual hours of television, but whose viewing patterns are very dedicated to particular media franchises, and whose engagement with these shows is more likely to spill over into face to face or online participation in social discussion or activities which centre on the shows that they watch. As Jenkins succinctly summarises, 'Loyals watch series; zappers watch television' (2006: 74). For producers, advertisers and sponsors, despite some shows with high numbers of loyals not necessarily being ratings winners in terms of overall viewership, the dedication which loyals attach to particular television programmes is increasingly seen as more valuable. A heightened attachment to a media franchise is thought to also mean related advertising is more effective. Thus, as Jenkins argues further, the "media industry is trying to generate content that will attract loyals, slow down zappers, and turn casuals into fans' (2006: 76). One of the key strategies being employed by the teams behind shows such as BSG for making and keeping loyal fans is providing multiple points of contact between the show's creative team and viewers, beyond the confines of the television episodes themselves.

The conversations and connections between BSG's creators and the show's fanbase run the full gamut of possible interactions. The official website of the SciFi Channe, SciFi.con hosts the more traditional material like promotional trailers, re-caps and an official discussion forum; the latter is very active, especially because some of the shows writers have publicly pointed out they read, and sometimes engage with, forum conversations with fans. Also, from the show's first season until today, the airing of each episode has been mirrored by the release of a new show-runner's podcast from Ronald D. Moore. These podcast commentaries offer fans insight into the production process, as well building a sense of personal connection between Moore and the show's fans. The podcast commentaries are also notable because they offer fans a view into the personal world of Moore as he and Terry Dresbach, Moore's wife, often include personal banter about the show and their lives in the podcast. Along similar lines, executive producer David Eick's episodic video blog ranges from set tours to interviews with cast and crew, all the way through to moments from production meetings and the writers' room. Nor is the extra BSG material produced in a one-way fashion; in 2007 SciFi.com launched the Battlestar Galactica Videomaker Toolkit which gave fans access to 
production media-stock footage, digital effects, score music and sound clips-which fans are encouraged to download and remix with their own footage to create fan-made BSG videos. Beyond the interactions facilitated by the show's producers, there are hundreds of BSGdedicated blogs and websites, and the collected knowledge of fans is showcased impressively at the Battlestar Wiki which is collectively authored by fans. ${ }^{1}$ Given these clever strategies used to build fan connectivity and interest, it was no surprise that in 2006 when the BSG producers announced they would release ten three to four minutes 'webisodes' in the weeks leading up to the third season premiere of the show, there was considerable fan excitement across the globe.

The BSG webisodes blur the line between promotional material and actual episodes as they were produced and acted by the same cast and crew who feature in the television series. For fans, this blurring was fantastic since it meant the free webisodes were a taste of the coming season and, played back to back, were almost the length and quality of a full episode of the show. The Writers Guild of America (WGA) also found the ambiguities of being neither clearly actual episodic television or just a web extras challenging, and decided the webisodes ultimately were more the former, causing an industrial dispute since writers are paid little or nothing for promotional material (which was NBC's position) in contrast to 'proper' TV episodes (Moore, 2006; Glater, 2006). Moreover, the studio line that any and all online material is promotional and thus not subject to the usual payment residuals for writers, actors and so forth - be it webisodes, or even full episodes - was central to the large-scale 2007 strike by WGA members. As Moore argued: "The notion that just because it's on your computer as opposed to your television set is absurd.... Your television and your computer are going to become the same device within the foreseeable future" (Goldman, 2007). However, the issue of charging for webisodes was never raised during WGA strike; the studios already make money from the advertising watched before each and every viewing of a webisode online. Moore and the BSG team simply wanted the studios to recognise the value of these webisodes, and the value of full episodes online, both in advertising terms and in terms of building fan connection with the BSG franchise.

That WGA drama aside, the webisodes gained a largely positive reaction across the web and in the mainstream press. For example, a report in The New York Times noted about the webisodes:

The "Galactica" segments are part of a broader effort by NBC Universal, which owns $\mathrm{Sci} \mathrm{Fi}$, to make new, original video and audio material - content - available on the Internet. ... The channel bills the Web segments move as a promotion to drum up interest in the third season of the series. "This is a way to get people talking about the show a month before it airs," said Craig E. Engler, general manager of SciFi.com. (Glater, 2006)

While there were some challenges for writers in trying to craft, at most, four-minute segments that could be meaningful both on their own terms, and as a series, in terms of actual views on the web, the webisodes were a huge hit. As Sci Fi reported in a press statement, the "first two instalments generated 1.2 million streams in one week, achieving in seven days more than half the total number of streams Sci Fi Pulse delivered in the previous month' (Sci Fi Wire,

\footnotetext{
${ }^{1}$ For the Battlestar Galactica discussion forum visit http://forums.scifi.com/index.php?showforum=24; for Ronald D. Moore's podcasts see http://www.scifi.com/battlestar/downloads/podcast/; for David Eick's videoblog visit http://video.scifi.com/player/?id=3256; and for the Battlestar Galactica Videomaker Toolkit see http://www.scifi.com/battlestar/videomaker/. On the fan side, the Battlestar Wiki is located at http://en.battlestarwiki.org/wiki/Main_Page.
} 
2006). The buzz around webisodes clearly worked, yet, despite the webisodes being promoted as free online content, when citizens of Australia, the UK, Canada or any other country outside the US tried to view these webisodes, they were met with a notice saying: "We're sorry, but the clip you selected isn't available from your location." (See Figure 1.) With that notice, loyal fans across the globe, but outside the US, found themselves subjected to the tyranny of digital distance, because, despite the technical means being available to share the webisodes globally, an economic decision was made to restrict the content along national boundaries. It is also worth noting that the BSG example is not unique; for the revived Doctor Who series, the $\mathrm{BBC}$ have put a lot of material online, too, including oneminute 'Tardisodes' which were less elaborate than the BSG webisodes, but still a lot more than just an advertisement. The tardisodes, too, despite being online content, were restricted to certain geographic areas. Similar to the arbitrary region locking of DVDs along national lines, but effectively carving the globe up into differentially manageable sales opportunities of interest only to media conglomerates, the geographic locking of the webisodes and similar online content illustrates distribution practices of only historical value, desperately ignoring the possibilities afforded by networks and technologies in the twenty-first century.

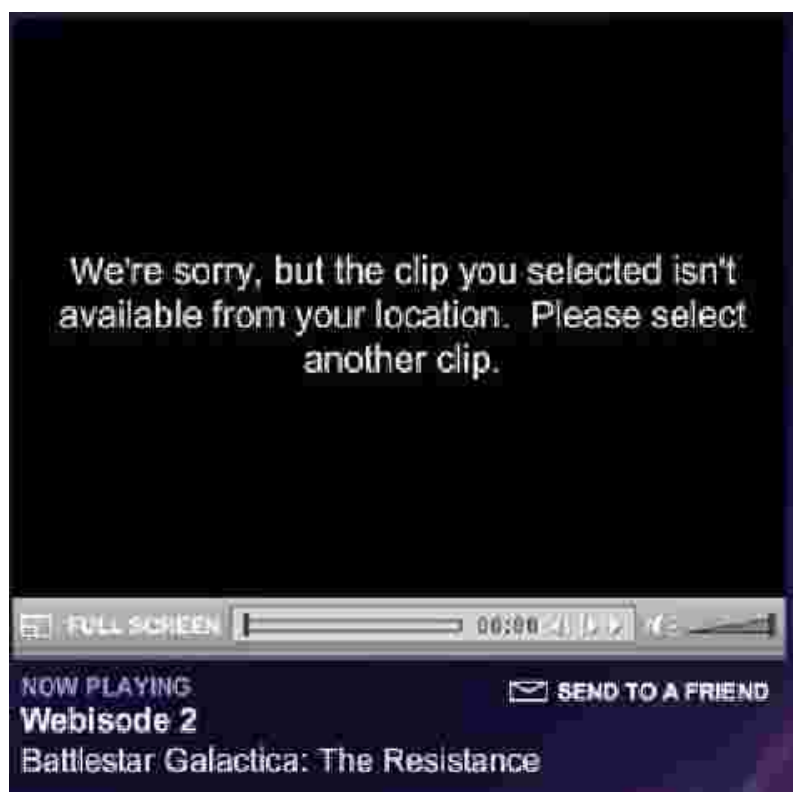

Figure 1. Screen-capture from http://www.scifi.com/battlestar/, 11 September 2006.

When NBC/Universal, the company who own the Sci Fi Channel, decided to restrict the BSG webisodes to viewers within the United States, they implied that the primary audience of the show was not global, but American. However, that notion is at odds with the ways in which the show's creative team engage with fans across the world and via the World Wide Web, building loyals across the globe, not just across the US. Since the official forums, Moore's podcasts, Eick's video blogs and other online material allowed global participation up to that point, many fans outside of the US who felt included in the extended culture around BSG, suddenly felt a rather negative change in the way they were regarded by the show's distributors. The different approaches might also be indicative of those owning the rights of distribution, NBC/Universal, and the creative team behind the show, led by Ronald D. Moore, holding different notions of 'the audience' of BSG. However, the decision to restrict the webisodes using technical means was quickly overridden by the ingenuity and camaraderie of the BSG fan community; within hours of each webisode appearing on the Sci Fi Channel online, they popped up both on video sharing websites such YouTube-which were eventually 
removed after copyright infringement complaints from NBC/Universal—and made available via peer to peer file-sharing services like BitTorrent, which proved far more challenging to control. Moreover, given the ease with which BSG fans found ways around a decision which appeared to them as an arbitrary geographic restriction, it comes as no surprise that the full episodes of BSG are also shared across the globe via digital peer to peer networks in a similar fashion.

According to a study done by the monitoring group Envisional, in terms of a percentage of global web traffic, Australians are the second largest downloaders of TV programs in the world, behind the UK in first place, and in front of the US in third (Pasick 2005). On a per capita basis, Australians are thus miles ahead, downloading far more television than any other country. The most downloaded shows tend to be those pitched at the teen market, and science fiction series; the former likely because most teens are digitally literate enough to find and download shows via peer to peer networks, and the latter because science fiction and other genre shows have always commanded the most loyal fans. While participating in the global social networks around certain shows, especially genre television, motivate some downloads, the single largest reason appears to be the delay time between their original airdates and US or UK-produced series being broadcast in Australia. As media scholar Alan McKee has noted on his move to downloading TV via peer to peer networks:

I'm a little bit addicted to a British television show called Doctor Who ... New episodes play in the UK about three months before they reach my homeland of Australia, and the wait was quite frankly becoming unbearable. Besides which, it was silly getting my parents to video every episode and post them out to me by airmail (which is what I'd been reduced to). (McKee, 2007)

According to research done by Alex $\mathrm{Malik}^{2}$, the 3 month delay for Doctor Who is uncharacteristically short, with the time between original airdates and broadcast in Australia now averaging over a year for many programs; for BSG, the release delay between US and Australia has crept into the 'six months or longer' category. Malik argues that the se 'delays are one of the major factors driving Australians to use BitTorrent and other internet-based peer-to-peer programs to download programs unlawfully from overseas, prior to their local broadcast' (Malik qtd in Moses, 2007). Thus, it appears there are at least four main pressures being felt by Australian BSG fans which leads them to try and view the show as close to the original US airdates as possible: firstly, for BSG, like many shows, there is a large delay between the US and Australian broadcast; secondly, BSG has received considerable critical acclaim and is thus written about in the mainstream press, increasing the likelihood of Australians coming across spoilers either from either this source or from fan-produced blog commentaries and similar material; thirdly, BSG is a genre series and thus already more likely to attract a dedicated fan-base; and finally, Moore and the show's creative team have actively courted and communicated with BSG fans across the world wide web for the entire duration of the current show, finding and creating many loyal viewers (as opposed to zappers). Add to this list the fact that peer to peer file-sharing technologies are increasingly easy to set up, and that the likelihood of being caught and sued is extremely low (since the practice of downloading is clearly unlawful, even for television, under the current Australian legal system), then it is hard to imagine why any BSG fans would wait 6 months or longer to view a show to which they feel so attached. Similarly, it is easy to understand why so many consumers find their own ways to circumvent the tyranny of digital distance when Australian television networks seem so unwillingly to change the way they do business.

\footnotetext{
${ }^{2}$ My thanks to Alex Malik for his help with finding sources for this article (via email correspondence in July, 2007).
} 
While Australian media distributors and TV networks have made very little, if any, moves to address the tyranny of digital distance, there are a few signs of hope on the horizon for viewers. One obvious option would be for free-to-air television to synchronise broadcast dates with the airdates in the US; another would be for Australian pay TV to catch up with the US cable system and take the lead in releasing first-run shows, not just repeats. In the foreseeable future, the latter options only seems possible for sporting events- the Australian Sci Fi Channel is simply rolling repeats of genre shows that have already been broadcast on free-to-air-but for higher-rating US series, there does appear some hope that commercial television in Australia will see more release dates synchronised, or closely aligned, with the original dates in other countries. Channel Seven recently began screening the popular USproduced shows Heroes and Prison Break within a fortnight of their initial US broadcast, matching an earlier effort made by Channel Ten to do the same thing with the first half of the first season of J ericho (Dunn, 2007). However, for shows which have many loyal fans, but not necessarily the overall numbers to command a prime-time slot, the immediate future is less rosy. In these cases, as for BSG, the most obvious option is for Australian distributors to become a portal for selling legally-downloadable episodes at the same time they become available in the US. Australian distributors might even partner with Apple as their US counterparts have, and use the Australian iTunes store as the distribution framework. ${ }^{3}$ At present, once a show like BSG is retired to a broadcast slot around midnight, it is of the least possible value to networks in terms of attracting advertising. In contrast, the very high level of fan loyalty, and the stability of that market, suggests that BSG might be of more value in Australia if every fan had a legal option to buy each episode for a reasonable price at the same time it is screened in the US. While some commentators looking at television downloads have dismissed the idea that Australian consumers would ever buy something they could get for free (Pesce, 2005), I would counter that for shows with high fan loyalty, a reasonably priced legal download would certainly be viable for that market. Currently, the only way for BSG fans to circumvent the tyranny of digital distance is through unlawful file-sharing; if a reasonably-priced legal option becomes available, the dedication of these fans would make it likely a fair number would opt to take up the opportunity.

The technical possibility and viewer desire for near-synchronous distribution of television in digital formats is currently at odds with aging Australian models of broadcast dates, and ideas about viewers being mainly passive, which were formed during the pre-digital era. This mismatch is the core of the tyranny of digital distance. However, returning to the work of Henry Jenkins, he plainly argues that 'few watch television in total silence and isolation. For most of us, television provides fodder for so-called water cooler conversations. And, for a growing number of people, the water cooler has gone digital' (2006: 26). Building on Jenkins' analogy, nobody likes to arrive at the water cooler only to discover they've missed the source of today's most interesting topics of conversation, but that is exactly what Australian television broadcasters are asking fans of overseas-produced television to do. Overcoming the tyranny of digital distance requires Australian television broadcasters to adapt to the needs and demands of their changing viewers, who are increasingly talking at the global water cooler, and want to be able to participate fully. In Blainey's original work on the

\footnotetext{
${ }^{3}$ While this may appear an argument that would further decrease the amount of Australian-produced content on broadcast te levision, although it is beyond the argument made here, I would suggest the same model of building high fan loyalty and providing a synchronous le gal download option across the world wide web could equally work for Australia-produced shows. Indeed, having more of the revenue flowing back into Australia on an epis ode by episode basis, rather than having to complete a season or more to sell it overseas, may be a financial blessing for Australia television producers.
} 
tyranny of distance (1966) he argued that it took the radical rupture of the Second World War to show that the distance from 'Empire' had to be overcome. Australian media distributors and television networks would be well served in thinking about this lesson unless they want to end up being the falling empire which is escaped in order to end the tyranny of digital distance.

Bibliography

'SCIFI.COM's Resistance Scores Big', Sci Fi Wire, 15 September 2006, http://www.scifi.com/scifiwire/index.php?id=38028 [accessed 16 September 2006].

Blainey, Geoffrey, 1966, The Tyranny of Distance, Sun Books, Melbourne.

Cuslidge, Tara and Jeffrey Weiss, 2007, 'Potter fans' new foe? The Web', PopMatters, 19 July, http://www.popmatters .com/pm/news/article/46121/potter-fans-new-foe-the-web/ [accessed 29 July 2007].

Dunn, Emily, 2007, 'Cult shows air sooner to curb downloads', The Sydney Morning Herald, 27 June, http://www.smh.com.au/news/tv--radio/cult-shows-air-sooner-to-curbdownloads/2007/06/26/1182623906754.html [accessed 28 June 2007].

Glater, Jonathan, 2006, 'Sci Fi Creates 'Webis odes' to Lure Viewers to TV', The New York Times, 5 September 2006, http://www.nytimes.com/2006/09/05/arts/television/05gala.html [ accessed 6 September 2006].

Goldman, Eric, 2007, 'Battlestar Galactica Producer Talks Strike: Ron Moore on why he's striking and how Battlestar's final season is affected', IGN, 7 November,

http://au.tv.ign.com/articles/833/833633p1.html [accessed 12 November 2007].

Gray, Jonathan and Jas on Mittell, 2007, 'Speculation on Spoilers: Lost Fandom, Narrative

Consumption and Rethinking Textuality', Particip@tions, 4, 1,

http://www.participations.org/Volume\%204/Is sue\%201/4_01_graymittell.htm [accessed 29 July 2007].

Jenkins, Henry, 1992, Textual poachers: Television Fans and Participatory Culture, Routledge: New York.

Jenkins, Henry, 2006, Convergence Culture: Where Old and New Media Collide, New York University Press, New York; London.

McKee, Alan, 2007, 'Will BitTorrent Change Television? A Luddite's View', Flow TV, 6, 4, 19 July, http://flowtv.org/?p=593 [accessed 29 July 2007].

Moore, Ronald D., 2006, 'Who Did What on the Webisodes', Ron Moore Blog, 6 September, http://blog.scifi.com/battlestar/archives/2006/09/\#a001251 [accessed 7 September 2006].

Moses, Asher, 2007, 'TV program delays "turning viewers into pirates"', The Age, 21 February, http://www.theage.com.au/news/home-theatre/tv-program-delays-turning-viewers-intopirates/2007/02/20/1171733750719.html, [accessed 21 February 2007].

Pasick, Adam, 2005, 'UK, Australia top TV piracy list', Australian IT, 18 February, http://www.australianit.news.com.au/story/0,24897,12292333-16123,00.html [accessed 28 July 2007].

Pesce, Mark, 2005, 'Piracy is Good? How Battlestar Galactica Killed Broadcast TV Part One: Hyperdistribution', Mindjack, 13 May, http://www.mindjack.com/feature/piracy051305.html [accessed 26 July 2007].

Reuters, 2007, 'Apple Says iTunes Sales Top 3 Billion Songs', The New York Times, 31 July, http://www.nytimes.com/reuters/technology/tech-apple-itunes.html [accessed 1 August 2007].

Wells, Peter, 2007, 'BitTorrent, Australia and TV Networks', MacTalk: The Australian Macintosh

Community, 12 June, http://forums.mactalk.com.au/showthread.php?t=32403 [accessed 28 July 2007]. 